\title{
Simultaneous Removal of Phosphate and Nitrate on Calcined Mg-Al Layered Double Hydroxides
}

\author{
Wei Liao", Xing-peng Liu², Hui-qiang Li ${ }^{1 *}$, Ping Yang ${ }^{1}$ \\ ${ }^{1}$ College of Architecture and Environment, Sichuan University, Chengdu 610065, China. \\ ${ }^{2}$ College of Communication Engineering, Chengdu Technological University, Chengdu 611730, China.
}

Received: 20 January 2018

Accepted: 8 September 2018

\begin{abstract}
The competitive adsorption of phosphate and nitrate from aqueous solution on calcined $\mathrm{Mg}-\mathrm{Al}$ layered double hydroxides (Mg-Al CLDHs) were investigated. Experiments were carried out as a function of adsorbent dosage, contact time, initial $\mathrm{pH}$ and temperature. The adsorption processes of phosphate and nitrate were followed by the pseudo second-order and pseudo first-order kinetics, respectively. The X-ray diffraction patterns (XRD) showed structural reconstruction during sorption, the unchanged $\mathrm{d}$-spacing $\mathrm{d}_{003}$ indicated phosphate and nitrate were mainly adsorbed on the surface and the near-edge interlayer. The results of Fourier transformed infrared spectroscopy (FTIR) verified nitrate and phosphate adsorbed onto the CLDHs. Desorption behaviors indicated that nitrate can be more easily desorbed from loaded CLDHs than phosphate. The possible mechanism of phosphate adsorption was controlled by chemisorption, while nitrate adsorption was governed by physisorption. The results showed that the Mg-Al CLDHs can be used to simultaneously remove phosphate and nitrate from aqueous solution.
\end{abstract}

Keywords: phosphate; nitrate; calcination; layered double hydroxides; desorption

\section{Introduction}

Eutrophication is caused by enrichment in nutrients, particularly phosphorus and nitrate. Eutrophication generally leads to algae and other aquatic vegetation bloom and degradation of water quality. In order to prevent eutrophication, it is of vital importance to reduce the load of phosphate and nitrate in a water environment. Phosphorus is widely used in industry, agriculture and household applications, which inevitably causes elevated concentrations of phosphorus in the environment. Therefore, it is important to remove phosphate, but difficult because of markedly low

*e-mail: lhq_scu@163.com concentrations [1]. Various techniques, including chemical precipitation [2], electrocoagulation [3], and adsorption [4] have been used for phosphate removal. Nitrate is one of the three nutrients of fertilizers, but it is also a potential hazard for human heath, especially to infants, causing blue baby syndrome [5]. The U.S. Environmental Protection Agency (EPA) sets the maximum contamination level of nitrate at $10 \mathrm{mg} / \mathrm{L}$ $\mathrm{NO}_{3}{ }^{-} \mathrm{N}$ in drinking water [5]. There are many methods for removing nitrate from water, i.e., catalytic [6], anion exchange membrane [7] and wetland [8]. Phosphate and nitrate also can be simultaneously removed by adsorption [9], reverse osmosis [10] and some bioreactors, such as SBR [11] and SAM [12]-. Among them, adsorption is regarded as the most promising method due to its simplicity and economy $[13,14]$. 
Layered double hydroxides (LDHs), known as hydrotalcites or anionic clay, have gained significant attention in recent decades. The general formula of LDHs can be represented as $\left[\mathrm{M}^{2+}{ }_{1-x} \mathrm{M}^{3+}{ }_{\mathrm{x}}(\mathrm{OH})_{2}\right]^{\mathrm{x}+}\left(\mathrm{A}^{\mathrm{n}-}\right)$ ${ }_{x / \mathrm{n}} \cdot \mathrm{mH}_{2} \mathrm{O}$, where $\mathrm{M}^{2+}$ and $\mathrm{M}^{3+}$ denote divalent and trivalent cations, $\mathrm{A}^{\mathrm{n}-}$ is the interlayer anion [15]. A high charge density of the sheets is generated from partial substitution of $\mathrm{M}^{2+}$ by $\mathrm{M}^{3+}$, which is compensated by interlayer anions [16]. The positive charge and exchangeable interlayer anion $\mathrm{A}^{\mathrm{n}-}$ make LDHs excellent anion adsorbents. The adsorption capacity of LDHs varied significantly with metal precursors, the interlayer anions, preparation methods and calcinations [17-19]. A great number of studies have been performed to explore the adsorption capacities of LDHs for iodate [20], phosphate [21], and anionic dye [22] from aqueous solution. LDHs have affinities for anions following the order of the Hofmeister series, the affinity increases with increasing charge and decreasing ionic radius [23]. Generally, LDHs have greater affinity for multivalent anions compared with monovalent anions. The $\mathrm{CO}_{3}^{2-}$ is considered as the most preferentially adsorbed anion, which inhibits adsorption for other anions. Many authors have reported that calcination markedly improved the adsorption ability as a result of the elimination of carbonate and enlargement of surface area and porosity [24]. Moreover, due to the memory effect, the calcined LDHs (CLDHs) can adsorb various anions through reconstruction of its original structure [25].

To the best of our knowledge, rare studies have been reported about competitive adsorption of phosphate and nitrate on LDHs. In this work, Mg-Al CLDHs were used to simultaneously remove phosphate and nitrate from aqueous solution. The objectives of this work are to investigate the influencing factors and desorption behaviors of the adsorbent. The competitive adsorption mechanisms of phosphate and nitrate on the Mg-Al CLDHs were also proposed.

\section{Experimental}

\section{Reagents and Chemicals}

All the chemicals (analytical grade) were directly used as they were received. $\mathrm{MgCl}_{2} \cdot 6 \mathrm{H}_{2} \mathrm{O}, \mathrm{AlCl}_{3} \cdot 6 \mathrm{H}_{2} \mathrm{O}$, $\mathrm{NaOH}, \mathrm{Na}_{2} \mathrm{CO}_{3}, \mathrm{KH}_{2} \mathrm{PO}_{4}$, and $\mathrm{KNO}_{3}$ were commercially purchased from Chengdu Kelong chemical reagent factory (China). The solution used in this study was synthetic wastewater, and it was prepared by $\mathrm{KH}_{2} \mathrm{PO}_{4}$ and $\mathrm{KNO}_{3}$ in distilled water.

\section{Synthesis}

Mg-Al LDHs were synthesized by co-precipitation method. Two solutions, solution I $(250 \mathrm{~mL})$ containing $0.3 \mathrm{M} \mathrm{MgCl} \cdot 6 \mathrm{H}_{2} \mathrm{O}$ and $0.1 \mathrm{M} \mathrm{AlCl} \cdot 6 \mathrm{H}_{2} \mathrm{O}$ and solution II $(250 \mathrm{~mL})$ containing $0.8 \mathrm{M} \mathrm{NaOH}$ and
$0.2 \mathrm{M} \mathrm{Na}_{2} \mathrm{CO}_{3}$, were added simultaneously to a $1 \mathrm{~L}$ beaker containing $100 \mathrm{~mL}$ of distilled water under vigorous stirring. The $\mathrm{pH}$ was maintained at 10 by the addition of $2 \mathrm{M} \mathrm{NaOH}$. The slurry was then aged at $65^{\circ} \mathrm{C}$ for $18 \mathrm{~h}$ and then centrifuged and washed thoroughly with distilled water until the washings were neutral. The precipitate was dried at $85^{\circ} \mathrm{C}$ overnight. The calcined product was obtained at $500^{\circ} \mathrm{C}$ for $5 \mathrm{~h}$ in a muffle furnace, which was denoted as CLDHs.

\section{Characterization}

The specific surface areas and pore structures of the samples were detected by nitrogen adsorption based on Brunauer-Emmett-Teller (BET) and Barrett-JoinerHalenda (BJH) methods using a surface area analyzer (ASAP2020, USA). The X-ray powder diffraction (XRD) patterns were carried out by a powder diffractometer using $\mathrm{Cu} \mathrm{K} \alpha$ radiation at a scanning speed of $2^{\circ} \mathrm{min}^{-1}$ (PANalytical B.V., Holland). Fourier transformed infrared spectroscopy (FTIR) spectra of the samples were measured by FTIR spectrophotometer using $\mathrm{KBr}$ pellets over a range of $4000-400 \mathrm{~cm}^{-1}$ (Nicolet 6700, America). X-ray photoelectron spectroscopy (XPS) tests were measured on an AXIS Ultra DLD (Shimadu, Japan) using a monochromatic Al K $\alpha$ X-ray source.

\section{Batch Experiments}

The phosphate and nitrate removal experiments were carried out at the initial concentration of $5 \mathrm{mg}-\mathrm{P} / \mathrm{L}$ phosphate and $30 \mathrm{mg}-\mathrm{N} / \mathrm{L}$ nitrate. The adsorption experiments were carried out in $250 \mathrm{~mL}$ glass conical flasks by adding a certain amount of adsorbent in $100 \mathrm{~mL}$ of synthetic mixed solution. After continuous stirring over a magnetic stirrer at $500 \mathrm{rpm}$ for a predetermined time interval, the supernatant was immediately filtered through a $0.45-\mu \mathrm{m}$ membrane for particle removal. The effects of dose, contact time, initial $\mathrm{pH}$, and temperature on phosphate and nitrate removal were studied. The initial $\mathrm{pH}$ of the solution was adjusted by the addition of $0.1 \mathrm{M} \mathrm{HCl}$ or $\mathrm{NaOH}$ solution and the supernatant $\mathrm{pH}$ was measured. The total volume added for $\mathrm{pH}$ adjustment never exceeded $1 \%$ of the total volume. The residual concentration of phosphate was determined by molybdate blue spectrophotometric method. The residual concentration of nitrate was determined by dual wavelength violet spectrophotography. Each run was made in duplicate.

Desorption experiments were carried out by immersing $0.2 \mathrm{~g}$ used CLDHs in $20 \mathrm{~mL}$ desorbent solutions over a range of concentrations to evaluate phosphate and nitrate desorption. After $16 \mathrm{~h}$ of interaction at room temperature (about $25^{\circ} \mathrm{C}$ ), the supernatant was filtered through a $0.45-\mu \mathrm{m}$ membrane to determine the extent of phosphate and nitrate release. 


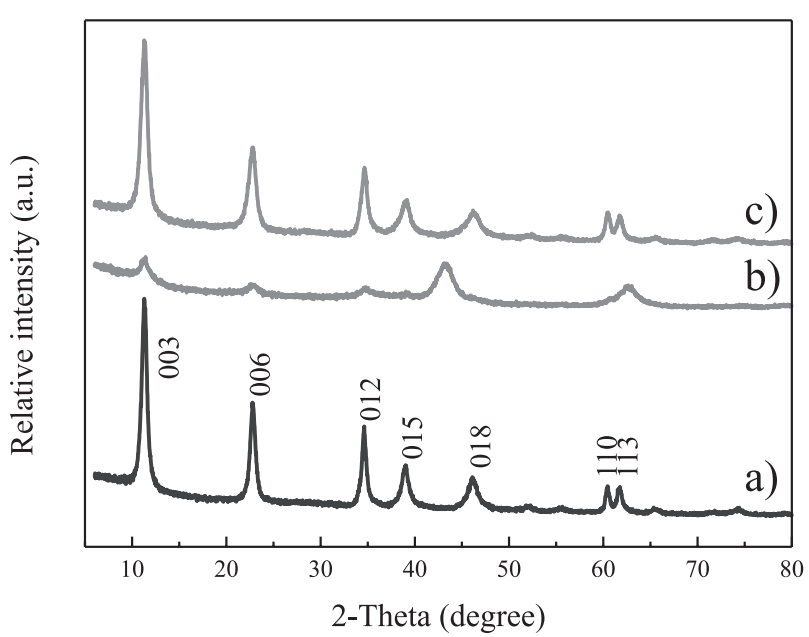

Fig. 1. XRD patterns of a) Mg-Al LDHs, b) Mg-Al CLDHs and c) Mg-Al CLDHs after adsorption.

\section{Results and Discussion}

\section{Characterization}

The XRD patterns of Mg-Al LDHs, CLDHs and CLDHs after phosphate and nitrate adsorption for $8 \mathrm{~h}$ are illustrated in Fig.1. In Fig. 1a), a series of (001) peaks appeared as sharp and intense symmetric lines at low $2 \theta$ values and clear (110), (113) reflections at high $2 \theta$ values, indicating characteristic basal reflections of hydrotalcite-like materials. The interlayer $d$-spacing $d_{003}$ and $\mathrm{d}_{006}$ of Mg-Al LDHs were found to be $0.786 \mathrm{~nm}$ and $0.392 \mathrm{~nm}$, the $\mathrm{d}_{003}$ was about twice as much as $\mathrm{d}_{006}$, indicating a favorable layer structure. The reflections were indexed to a hexagonal lattice with rhombohedral 3R symmetry [26]. The XRD pattern in Fig. 1b) showed that the phases of LDHs disappeared and were replaced by phases of metal oxides after calcination at $500^{\circ} \mathrm{C}$ for $5 \mathrm{~h}$.

The FTIR spectrums of Mg-Al LDHs, CLDHs and CLDHs after adsorption of phosphate and nitrate for $8 \mathrm{~h}$ are represented in Fig. 2. The absorption bands

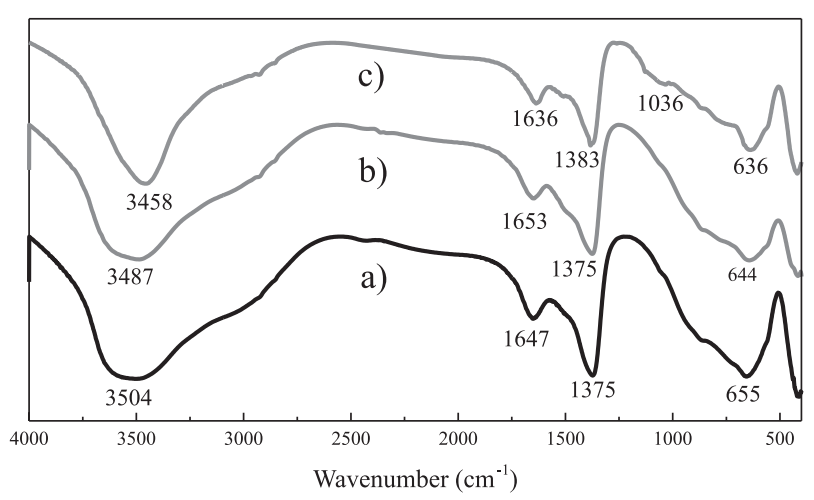

Fig. 2. FTIR spectra of a) Mg-Al LDHs, b) CLDHs and c) CLDHs after adsorption.

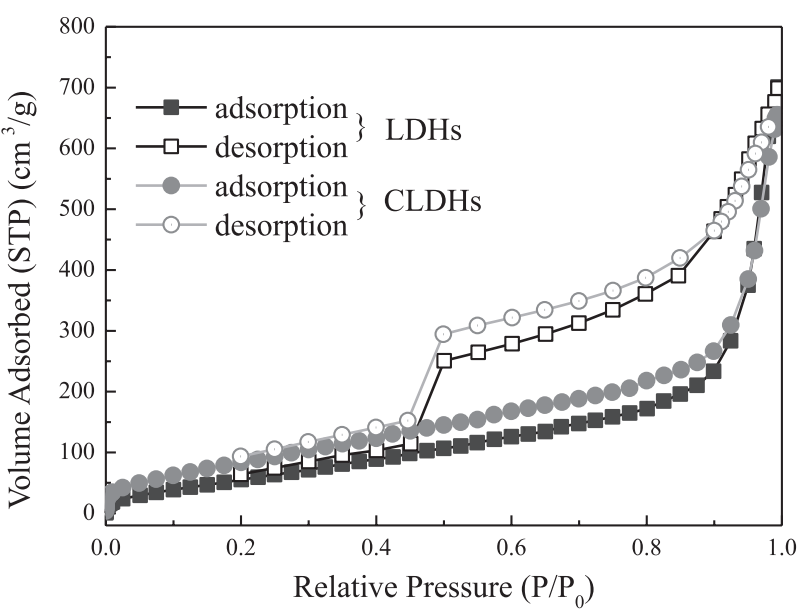

Fig. 3. Isotherm curve of $\mathrm{N}_{2}$ adsorption-desorption.

around $3500 \mathrm{~cm}^{-1}$ and $1700-1610 \mathrm{~cm}^{-1}$ belong to $\mathrm{OH}$ stretching vibration of hydroxyl groups, water molecules in the interlayer and physically adsorbed water [27, 28]. The absorption bands at $644 \mathrm{~cm}^{-1}$ are assigned to the stretching mode of $\mathrm{M}-\mathrm{O}$ and $\mathrm{O}-\mathrm{M}-\mathrm{O}(\mathrm{M}=\mathrm{Mg}, \mathrm{Al})$ [29]. The band at $1375 \mathrm{~cm}^{-1}$ is due to the stretching vibrations of carbonate [30]. After calcination, the intensities of the $\mathrm{OH}$ band and $\mathrm{C}-\mathrm{O}$ band were lowered, revealing that water molecules and carbonate were partial lost but not completely removed during the thermal treatment. Hibino et al. [31] demonstrated that $20-30 \%$ of the carbonates still remained in CLDHs at the calcination temperature of $500^{\circ} \mathrm{C}$. After adsorption, the appearance of a sharp band at $1384 \mathrm{~cm}^{-1}$ was attributed to the vibration of $\mathrm{NO}_{3}^{-}$anions [32], and the presence of bands at $1036 \mathrm{~cm}^{-1}$ would be characteristic of phosphate [33, 34], which ascertained the adsorption of nitrate and phosphate on Mg-Al CLDHs.

The nitrogen adsorption-desorption isotherms of raw $\mathrm{Mg}-\mathrm{Al} \mathrm{LDHs}$ and calcined products are shown in Fig. 3 and the porous structure parameters are compiled in Table 1. All the isotherms are type III-like adsorption isotherms with an H3-type hysteresis loop for the desorption isotherms according to the IUPAC classification, which is observed with aggregates of plate-like particles giving rise to slit-shaped pores. After calcination, the surface area and the average pore diameter increased. For adsorbents, a large surface area can provide more adsorption sites. As a consequence, calcination leads to increased adsorption capacities, which may be attributed to the surface bonding in a

Table 1. Surface area and pore properties of the raw $\mathrm{Mg}-\mathrm{Al}$ and the calcined Mg-Al samples.

\begin{tabular}{|c|c|c|c|}
\hline Samples & $\begin{array}{c}\text { Surface area } \\
\left(\mathrm{S}_{\mathrm{BET}}\right)\left(\mathrm{m}^{2} / \mathrm{g}\right)\end{array}$ & $\begin{array}{c}\text { Pore volume } \\
\left(\mathrm{cm}^{3} / \mathrm{g}\right)\end{array}$ & $\begin{array}{c}\text { Average pore } \\
\text { diameter } \\
(\mathrm{nm})\end{array}$ \\
\hline Mg-Al LDHs & 264.47 & 1.08 & 16.37 \\
\hline Mg-Al CLDHs & 351.24 & 1.01 & 57.69 \\
\hline
\end{tabular}




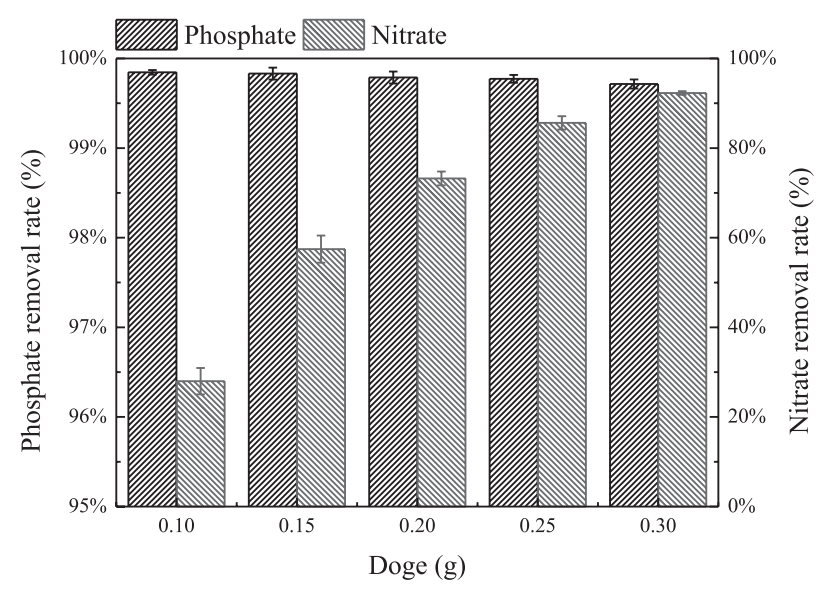

Fig. 4. Variation of adsorbent dose on phosphate and nitrate removal.

physical adsorption or physical sorption onto the solid surface [15]. The average pore sizes followed the size range $(2-50 \mathrm{~nm})$ of mesoporous materials. These results indicated the mesoporous structures and high surface area of the synthesized products.

\section{Adsorbent Dose}

The variation of adsorbent dose on removal of phosphate and nitrate from aqueous solution with MgAl CLDHs are shown in Fig. 4. The removal efficiency of nitrate improved with increasing dosage of the CLDHs. With the enhancement in the adsorbent dose from 0.1 to $0.3 \mathrm{~g}$ in $100 \mathrm{~mL}$ mixture solution, the nitrate removal efficiencies increased from $27.98 \%$ to $92.29 \%$. The phosphate removal rates exceeded $99.84 \%$ at the dose of $0.1 \mathrm{~g}$, which showed that the CLDHs had preferential adsorption for phosphate. Nitrate cannot compete with phosphate for adsorption sites, and even the initial concentration of nitrate was much lower than that of phosphate. When adsorption sites were insufficient, phosphate was suppressed by the competition of nitrate. By the enhancement of CLDH

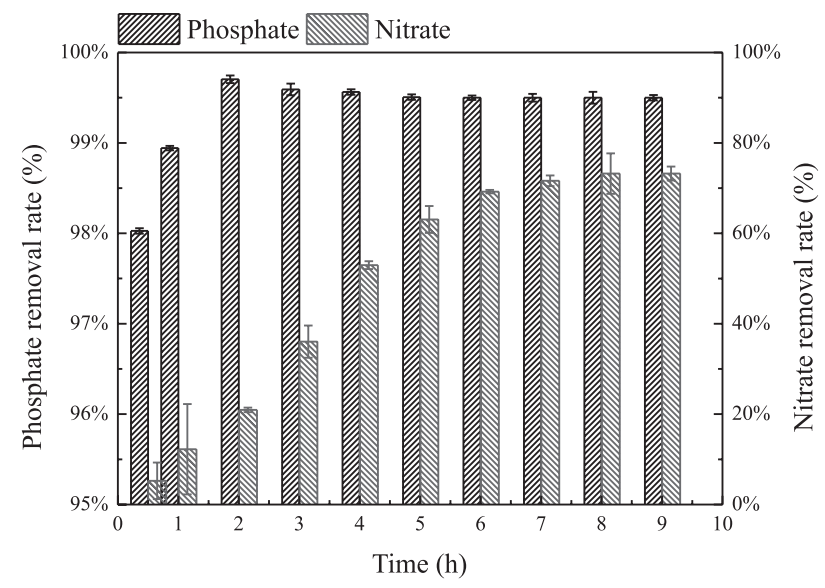

Fig. 5. Effect of reaction time on phosphate and nitrate removal. dose, the numbers of adsorption sites increased, and consequently the competitive effect of phosphate on nitrate adsorption decreased. With the addition dose of $0.2 \mathrm{~g}$, the percentage removal of phosphate and nitrate were $99.79 \%$ and $73.22 \%$, and the residual concentration of phosphate $(0.01 \mathrm{mg}-\mathrm{P} / \mathrm{L})$ and nitrate $(8.03 \mathrm{mg}-\mathrm{N} / \mathrm{L})$ reached the discharge standards. In consideration of economic efficiency and removal efficiency, $0.2 \mathrm{~g}$ was chosen as the appropriate dose in the following studies.

\section{Reaction Time}

Most of the adsorption transformation processes are time dependent. As illustrated in Fig. 5, the removal rates of phosphate and nitrate improved with the proceeding of the adsorption. The adsorption equilibriums were established after $2 \mathrm{~h}$ for phosphate and $8 \mathrm{~h}$ for nitrate. The adsorption velocity of phosphate was faster than that of nitrate, when $98 \%$ of adsorption occurred at the first $30 \mathrm{~min}$ for phosphate. This may due to the adsorptive affinity between CLDHs, and phosphate was stronger. Cai [23] reported the adsorption of fluoride and phosphate on CLDHs in a single or binary system took nearly $24 \mathrm{~h}$ to achieve the equilibrium. Halajnia [35] reported about $86.4 \%$ of nitrate adsorption by Mg-Al (3:1) occurring within the first $10 \mathrm{~min}$ and the adsorption equilibrium attained after $30 \mathrm{~min}$. But in this work, with the addition of phosphate, it took $8 \mathrm{~h}$ for nitrate to reach equilibrium. This might be explained as phosphate was preferentially adsorbed onto the surface of CLDHs, while negatively charged phosphate repelled nitrate with the same charge. The adsorption equilibrium depended on the types of LDHs, initial concentration as well as co-existing anions. To ensure that phosphate and nitrate reached saturation adsorption, the contact time was set at $8 \mathrm{~h}$ in further studies.

In order to clarify the dynamic interactions of phosphate and nitrate with CLDHs, three kinetics models, including pseudo first-order, pseudo secondorder and intraparticle diffusion kinetics models were used to fit experimental data of phosphate and nitrate adsorption. The mathematical forms and parameters of the kinetic models are presented in Table 2.

The kinetic experiment data of phosphate was in best agreement with the pseudo second-order model based on the high correlation coefficient $\mathrm{R}^{2}$. This model assumed that chemical adsorption was the rate-limiting step, indicating that the phosphate adsorption process was governed by chemisorptions or chemical bonding between adsorbent active sites and phosphate. According to Yang [28], the surface hydroxyl groups (M-OH) of LDHs could be exchanged by the adsorbed phosphate. On the other hand, CLDHs generated positive charges, electrostatic attraction happened between anions and the brucite-like sheet which enhanced the adsorption. Hence the adsorption mechanisms of phosphate were attributed to chemical sorption involving ligand complexation and electrostatic attraction. For nitrate adsorption, the experiment data showed a better fitting with the 
Table 2. Mathematical forms and parameters of the kinetic models.

\begin{tabular}{|c|c|c|c|c|}
\hline Kinetic model & Linear form of model & Parameters & Phosphate & Nitrate \\
\hline \multirow{3}{*}{ Pseudo-first-order } & \multirow{3}{*}{$\ln \left(\mathrm{q}_{\mathrm{e}}-\mathrm{q}_{\mathrm{t}}\right)=\ln \left(\mathrm{q}_{\mathrm{e}}\right)-\mathrm{k}_{\mathrm{l}} \mathrm{t}$} & $\mathrm{k}_{1}\left(\min ^{-1}\right)$ & 8.4277 & 0.1656 \\
\hline & & $\mathrm{q}_{\mathrm{e}}(\mathrm{mg} / \mathrm{g})$ & 2.49 & 15.25 \\
\hline & & $\mathrm{R}^{2}$ & 0.8318 & 0.9649 \\
\hline \multirow{3}{*}{ Pseudo-second-order } & \multirow{3}{*}{$\mathrm{t} / \mathrm{q}_{\mathrm{t}}=1 /\left(\mathrm{k}_{2} \mathrm{q}_{\mathrm{e}}^{2}\right)+\mathrm{t} / \mathrm{q}_{\mathrm{e}}$} & $\mathrm{k}_{2}(\mathrm{~g} /(\mathrm{mg} \cdot \mathrm{min}))$ & 179.38 & 0.000759 \\
\hline & & $\mathrm{q}_{\mathrm{e}}(\mathrm{mg} / \mathrm{g})$ & 2.49 & 50 \\
\hline & & $\mathrm{R}^{2}$ & 1 & 0.3633 \\
\hline \multirow{4}{*}{ Intraparticle diffusion } & \multirow{4}{*}{$\mathrm{q}_{\mathrm{t}}=\mathrm{k}_{\mathrm{ip}} \mathrm{t}^{1 / 2}+\mathrm{C}$} & $\mathrm{k}_{\mathrm{ipl} 1}$ & 0.0427 & 5.7505 \\
\hline & & $\mathrm{R}^{2}$ & 0.8763 & 0.9604 \\
\hline & & $\mathrm{k}_{\mathrm{ip} 2}$ & 0.0018 & 1.1254 \\
\hline & & $\mathrm{R}^{2}$ & 0.7464 & 0.8824 \\
\hline
\end{tabular}

pseudo first-order model. The same type of kinetic model was reported in a study of nitrate adsorption on Ca-Al-LDHs [36]. The intraparticle diffusion kinetic model elaborated upon the internal mass transfer in the adsorption process. The y-intercepts were nonzero, thus indicating that intraparticle diffusion was not the sole rate-limiting factor for adsorption on CLDHs [32]. The corresponding results of fitting experiment data were multilinear, which indicated two stages of influence on phosphate and nitrate adsorption processes. The first stage was the adsorption over the shell and macropore of adsorbents, and the second stage could be attributed to the intraparticle diffusion through micropores [37].

\section{Solution $\mathrm{pH}$}

Solution $\mathrm{pH}$ is one of the most important parameters affecting adsorption efficiency. The effect of $\mathrm{pH}$ on adsorption in a binary system was studied in the $\mathrm{pH}$ range of 2-12 at an initial phosphate concentration of $5 \mathrm{mg}-\mathrm{P} / \mathrm{L}$ and an initial nitrate concentration of $30 \mathrm{mg}-\mathrm{N} / \mathrm{L}$. As illustrated in Fig. 6, the effect of initial $\mathrm{pH}$ on phosphate adsorption was insignificant. The percentage removal of phosphate exceeded 99\%. On strong acid or alkali condition, the removal rate was slightly decreased. Under extreme conditions, partial CLDHs were structurally destroyed, but phosphate can be effectively removed by CLDHs even at a low dose. At high $\mathrm{pH}$ value, $\mathrm{PO}_{4}^{3-}$ may generate precipitation. In order to investigate the removal mechanism of phosphate at alkali conditions, a compensatory test was carried out by adding $0.2 \mathrm{~g}$ CLDHs in $100 \mathrm{~mL}$ of distilled water with a $\mathrm{pH}$ adjusted to 12. After continuous stirring for $8 \mathrm{~h}$, the concentrations of released $\mathrm{Mg}^{2+}$ and $\mathrm{Al}^{3+}$ were determined by ICP (data not shown). The results showed that the concentrations of released metal ions were very low. So, it is believed that precipitation was a secondary cause, while adsorption by CLDHs was the main reason for the removal of $\mathrm{PO}_{4}^{3-}$. The removal rates of nitrate adsorption for CLDHs were around $75 \%$ in the range of $\mathrm{pH}$ between 4 and 10 . With a further increase or decrease in $\mathrm{pH}$, the adsorption capacity was adversely affected. These results demonstrated that the adsorption of nitrate was susceptible to $\mathrm{pH}$. These can account for higher $\mathrm{pH}$ causes, increasing the competitive effect of $\mathrm{OH}^{-}$, phosphate existed as multivalent anions at higher $\mathrm{pH}$ values. According to Hofmeister series, LDHs have greater affinity for multivalent phosphate anions than monovalent $\mathrm{OH}$, and have greater affinity for $\mathrm{OH}^{-}$compared with nitrate. Moreover, the outstanding phosphate adsorption capacity of CLDHs partly mitigated the adverse influence in acid or alkali condition. On the other hand, a higher $\mathrm{pH}$ led the surface of the adsorbent to being negatively charged. Therefore, the anion adsorption was inhibited because of repulsive interaction [38]. In the lower $\mathrm{pH}$ range, the stability of the adsorbent structure was partly impaired and caused a decrease in adsorption [39].

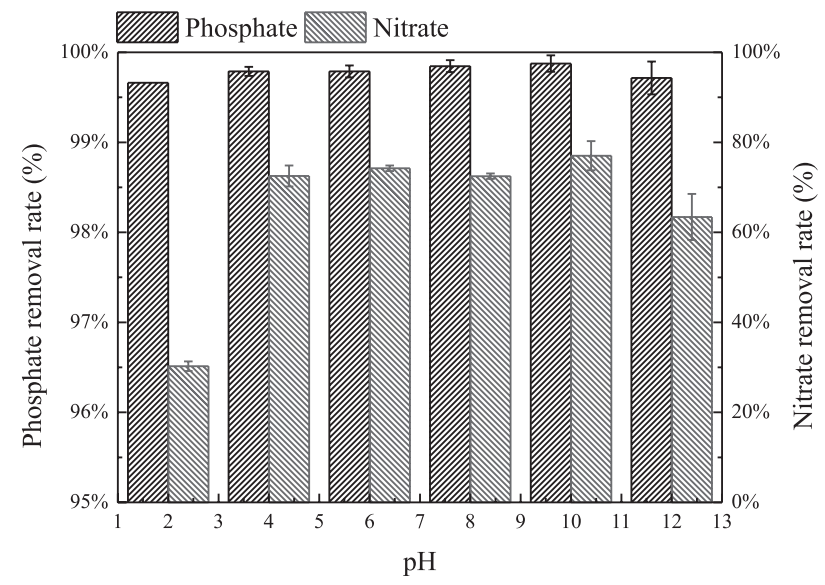

Fig. 6. Effect of initial $\mathrm{pH}$ on phosphate and nitrate removal. 


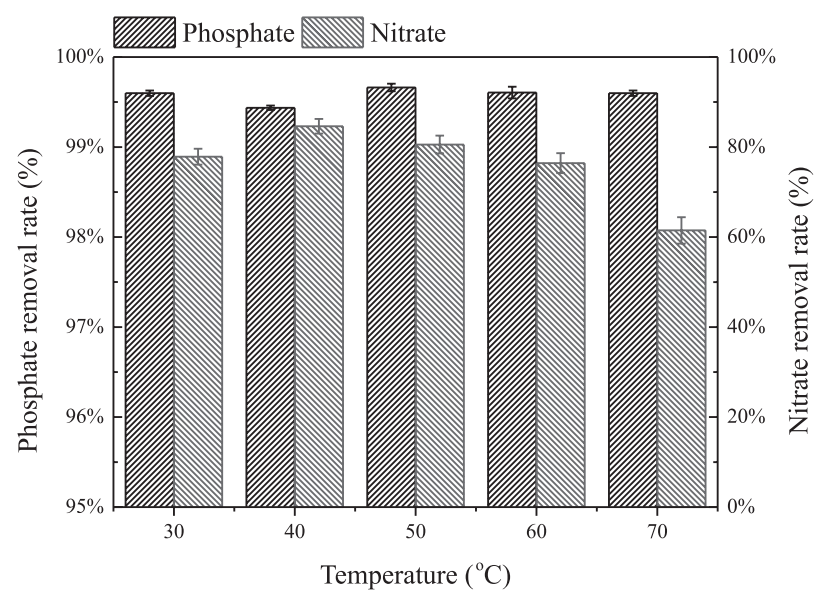

Fig. 7. Effect of temperature on phosphate and nitrate removal.

\section{Temperature}

The effect of temperature on the adsorption of phosphate and nitrate by CLDHs was studied. As illustrated in Fig. 7, the influence of temperature on the adsorption of phosphate was negligible. The percentage removal of phosphate fluctuated around $99.6 \%$. For nitrate adsorption, the percentage removal decreased from $84.61 \%$ to $61.49 \%$ with the temperature increasing from $40^{\circ} \mathrm{C}$ to $70^{\circ} \mathrm{C}$, which indicated that the interaction between nitrate and CLDHs was exothermic in nature. It could be deduced that the mechanism of nitrate adsorption was a spontaneous physical sorption. The increase in temperature gave a rise in entropy value, hence the higher temperature
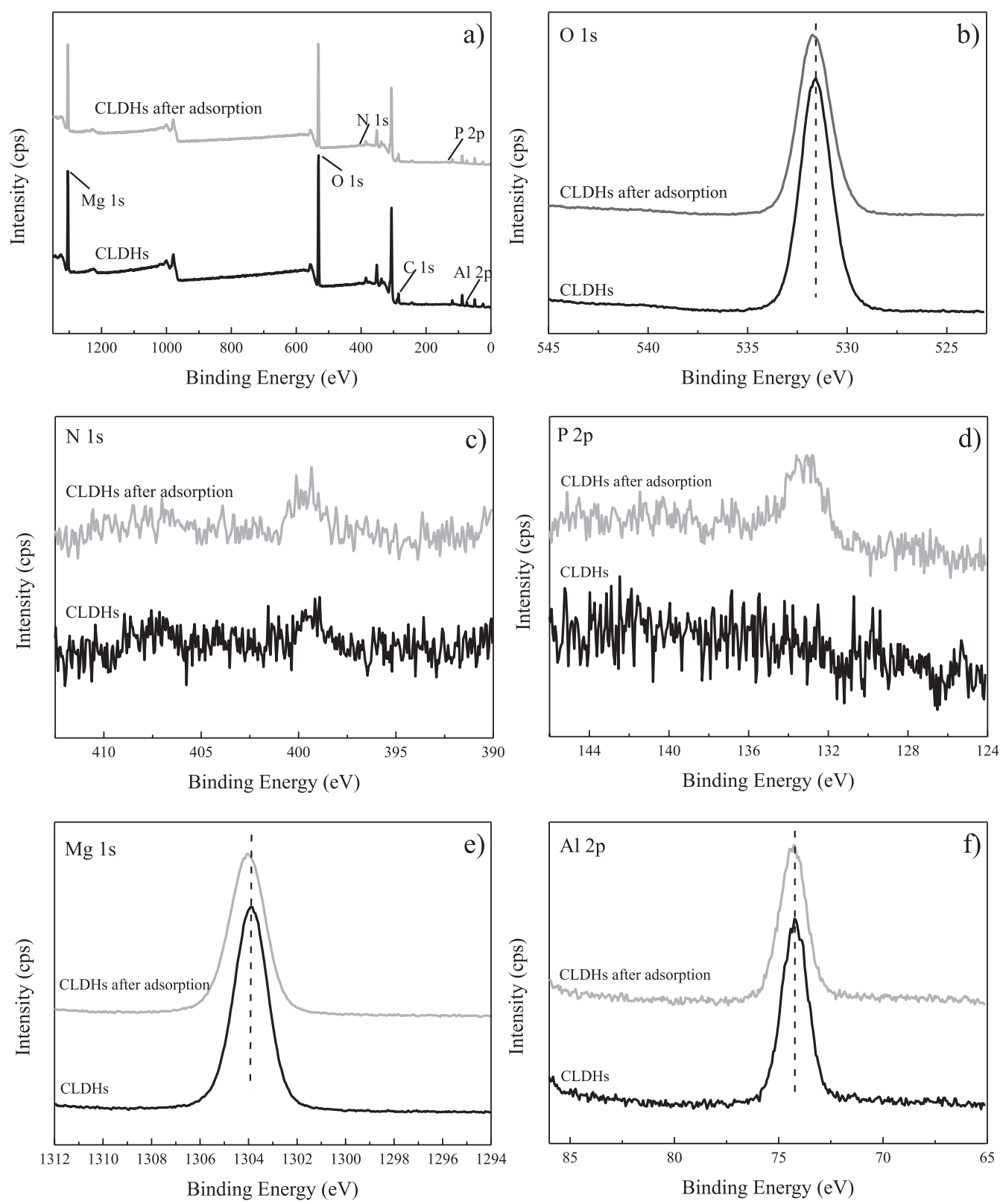

Fig. 8. Wide scan a), O 1s b), N 1s c), P 2p d), Mg 1s e) and Al 2p f) XPS spectra of the Mg-Al CLDHs before and after phosphate and nitrate adsorption. 
resulted in decreased adsorption capacity [37]. Halajnia [35] observed that nitrate adsorption by $\mathrm{Mg}-\mathrm{Fe}$ and $\mathrm{Mg}-\mathrm{Al}$ LDHs decreased with the increasing temperature. However, Tezuka [40] reported on the endothermic nature of nitrate adsorption on uncalcined Ni-Fe LDHs. This discrepancy might be attributable to the structural differences between the synthesized LDHs and different adsorption types.

\section{Possible Removal Mechanism over CLDHs}

The XRD pattern of CLDHs after adsorption of phosphate and nitrate in Fig. 1c) presented a similar pattern as the original precursor, implying that the $\mathrm{Mg}-\mathrm{Al}$ oxide underwent spontaneous rehydration reaction and structural reconstruction during the adsorption of phosphate and nitrate from aqueous solution. However, the $d$-spacing $d_{003}$ remained $0.786 \mathrm{~nm}$, indicating that the recovered LDHs had $\mathrm{CO}_{3}^{2-}$ in the interlayer, which may come from $\mathrm{CO}_{2}$ dissolved in the solution or residual in the CLDHs. As a consequence, phosphate and nitrate may not intercalate into the interlayer, but were mainly adsorbed on the surface and the near-edge interlayer. He et al. [18] demonstrated that adsorption of $\mathrm{HPO}_{4}^{2-}$ by $\mathrm{ZnAl}-400$ did not go through the structure memory effect or ion exchange, but reacted on the surface.

To further probe the mechanism of nitrate and phosphate adsorption onto Mg-Al CLDHs, the XPS spectra of the particles before and after sorption in a binary system for $8 \mathrm{~h}$ were evaluated. Wide scan XPS spectra of the fresh CLDHs indicated the presence of $\mathrm{Mg}, \mathrm{Al}, \mathrm{O}$ and $\mathrm{C}$ elements (Fig. 8a). The appearance of $\mathrm{N} 1 \mathrm{~s}$ and $\mathrm{P} 2 \mathrm{p}$ spectra after sorption signified the successful $\mathrm{P}$ and $\mathrm{N}$ binding to CLDHs (Fig. $8 \mathrm{c}-\mathrm{d}$ ). No obvious changes of $\mathrm{Al} 2 \mathrm{p}$ spectra were observed after sorption (Fig. 8f), indicating that $\mathrm{Al}$ atoms might not take in the sorption. In comparison with $\mathrm{Al} 2 \mathrm{p}$, the binding energy value of $\mathrm{Mg}$ 1s shifted to a higher value after sorption (Fig.8e), showing that $\mathrm{Mg}$ atoms played an important role in phosphate and nitrate adsorption, and the possible formation of inner sphere complexation. The O 1s spectra of CLDHs and CLDHs loaded with phosphate and nitrate were slightly different, implying the alteration of oxygen constituents of CLDHs after sorption (Fig. 8b).

\section{Desorption and Regeneration}

Assays of desorption were conducted using three types of solution, as shown in Table 3. Obviously, nitrate was more easily desorbed from loaded CLDHs than phosphate. For both phosphate and nitrate, higher desorption rates were obtained at higher concentrations of desorbent solution. The highest desorption efficiency of $94.68 \%$ for nitrate and $48.56 \%$ for phosphate were the performance of $1 \mathrm{M}$ $\mathrm{Na}_{2} \mathrm{CO}_{3}$ and $1 \mathrm{M} \mathrm{NaOH}$, respectively. Comparable removal for phosphate (43.53\%) and nitrate (94.24\%)
Table 3. Selection of solutions for phosphate and nitrate desorption.

\begin{tabular}{|c|c|c|}
\hline Desorption solution & $\begin{array}{c}\text { Desorption rate of } \\
\text { phosphate (\%) }\end{array}$ & $\begin{array}{c}\text { Desorption rate } \\
\text { of nitrate (\%) }\end{array}$ \\
\hline Distill water & $0.01 \pm 0.00$ & $43.30 \pm 0.00$ \\
\hline $0.01 \mathrm{M} \mathrm{NaOH}$ & $0.05 \pm 0.00$ & $68.22 \pm 1.31$ \\
\hline $0.1 \mathrm{M} \mathrm{NaOH}$ & $1.63 \pm 0.05$ & $76.10 \pm 1.31$ \\
\hline $1 \mathrm{M} \mathrm{NaOH}$ & $48.56 \pm 0.40$ & $85.50 \pm 0.22$ \\
\hline $0.01 \mathrm{M} \mathrm{Na}_{2} \mathrm{CO}_{3}$ & $4.19 \pm 0.18$ & $80.91 \pm 3.50$ \\
\hline $0.1 \mathrm{M} \mathrm{Na}_{2} \mathrm{CO}_{3}$ & $16.01 \pm 0.04$ & $89.22 \pm 0.44$ \\
\hline $1 \mathrm{M} \mathrm{Na}_{2} \mathrm{CO}_{3}$ & $38.11 \pm 0.28$ & $94.68 \pm 1.09$ \\
\hline $0.1 \mathrm{M} \mathrm{NaOH}_{+}$ & $45.53 \pm 0.20$ & $94.24 \pm 1.09$ \\
\hline $0.4 \mathrm{M} \mathrm{Na}_{2} \mathrm{CO}_{3}$ & $37.91 \pm 2.02$ & $93.37 \pm 5.28$ \\
\hline $0.1 \mathrm{M} \mathrm{NaOH}_{+}$ & $44.66 \pm 1.17$ & $65.16 \pm 0.44$ \\
\hline $0.1 \mathrm{MNa}_{2} \mathrm{CO}_{3}$ & $\begin{array}{c}0.4 \mathrm{M} \mathrm{NaOH} \\
0.1 \mathrm{M} \mathrm{Na}_{2} \mathrm{CO}_{3}\end{array}$ & \\
\hline
\end{tabular}

was achieved with the combination $0.1 \mathrm{M} \mathrm{NaOH}+$ $0.4 \mathrm{M} \mathrm{Na}_{2} \mathrm{CO}_{3}$. Nitrate can be desorbed efficiently by $\mathrm{Na}_{2} \mathrm{CO}_{3}$ solution, even at low concentrations of $\mathrm{Na}_{2} \mathrm{CO}_{3}$ solution. This may be ascribed to the anion exchange process, since it is easy for $\mathrm{CO}_{3}{ }^{2-}$ to displace $\mathrm{NO}_{3}{ }^{-}$. As for phosphate, once it was adsorbed, it would be hard to be desorbed. Hardly any phosphate was desorbed after interacting with distilled water, however, about $43.30 \%$ loaded nitrate was desorbed in distill water. For physical sorption, the intermolecular force between adsorbed anions and the surface of the adsorbent is intermolecular attraction, namely Van der Waals force. Physical sorption is a reversible process due to Van der Waals force being relatively weak. On the contrary, chemical sorption usually is an irreversible process for the reason that adsorbent-adsorbate is firmly combined by chemical bonds, which are much stronger than Van der Waals force. It can be concluded that nitrate adsorption by CLDHs was reversible by physical sorption. Otherwise, phosphate adsorption was mainly controlled by chemisorptions.

\section{Conclusions}

In the current work, the competitive adsorption of phosphate and nitrate by $\mathrm{Mg}$-Al CLDHs was investigated. Competition in adsorption between phosphate and nitrate was affected by dose, contact time, initial $\mathrm{pH}$ and temperature. Phosphate was preferentially adsorbed onto CLDHs, while nitrate was adsorbed when there were redundant adsorption sites. The adsorption of phosphate followed the pseudo second-order model, but the adsorption of nitrate was better fitted with the pseudo first-order model. During the adsorption of phosphate and nitrate, CLDHs reconstructed their 
original layered structure with an unchanged basal spacing. It can be deduced that the main adsorption mechanisms were surface adsorption and near-edge intercalation instead of ion exchange. The removal of phosphate was mainly controlled by ligand complexation or electrostatic attraction. Thus, desorption of phosphate was comparatively difficult. The removal of nitrate was controlled by physical sorption. Nitrate can be easily desorbed, especially with $\mathrm{Na}_{2} \mathrm{CO}_{3}$ solution through ion exchange.

\section{Acknowledgements}

This research was supported by the National Natural Science Founda-tion of China (No. 51308362) and the Foundation of Chengdu Technological University (No. 2017RC014).

\section{Conflict of Interest}

The authors declare no conflict of interest.

\section{Reference}

1. CHITRAKAR R., TEZUKA S., SONODA A., SAKANE K., OOI K., HIROTSU T. Adsorption of phosphate from seawater on calcined MgMn-layered double hydroxides. J COLLOID INTERF SCI. 290, 45, 2005.

2. SUN W., MA G., SUN Y., LIU Y., SONG N., XU Y., ZHENG $\mathrm{H}$. Effective treatment of high phosphorus pharmaceutical wastewater by chemical precipitation. CAN J CHEM ENG. 95, 2017.

3. MALINOVIĆ B.N., ATLAGIĆ S.G., MALINOVIĆ T., BJELAJAC N., MILOVANOVIĆ A. Phosphate removal from wastewater by electrocoagulation process using aluminium electrode. in: Meeting of the Serbian Chemical Society. 2016.

4. ZELMANOV G., SEMIAT R.The influence of competitive inorganic ions on phosphate removal from water by adsorption on iron $\left(\mathrm{Fe}^{+3}\right)$ oxide/hydroxide nanoparticlesbased agglomerates. J. Water Process ENG. 5, 143,2015.

5. XUE L., GAO B., WAN Y., FANG J., WANG S., LI Y., MUÑOZ-CARPENA R., YANG L. High efficiency and selectivity of MgFe-LDH modified wheat-straw biochar in the removal of nitrate from aqueous solutions. J TAIWAN INST CHEM E. 63, 312, 2016.

6. GARCÍAFERNÁNDEZ M.J., BUITRAGOSIERRA R., PASTORBLAS M.M., SOARES O.S.G.P, PEREIRA M.F.R., SEPÚLVEDAESCRIBANO A. Green synthesis of polypyrrole-supported metal catalysts: application to nitrate removal in water. Rsc Advances. 5, 32706, 2015.

7. HAMOUDA S.B., TOUATI K., AMOR M.B. Donnan dialysis as membrane process for nitrate removal from drinking water: Membrane structure effect. ARAB J CHEM. 10, S287, 2017.

8. PARK J.H., KIM S.H., DELAUNE R.D., CHO J.S., HEO J.S., YONG S.O., SEO D.C. Enhancement of nitrate removal in constructed wetlands utilizing a combined autotrophic and heterotrophic denitrification technology for treating hydroponic wastewater containing high nitrate and low organic carbon concentrations. AGR WATER MANAGE. 162, 1, 2015.

9. YOSHINO H., TOKUMURA M., KAWASE Y. Simultaneous removal of nitrate, hydrogen peroxide and phosphate in semiconductor acidic wastewater by zerovalent iron. J Environ Sci Health A Tox Hazard Subst Environ Eng. 49, 998, 2014.

10. WANG X.X., WU Y.H., ZHANG T.Y., XU X.Q., DAO G.H., HU H.Y. Simultaneous nitrogen, phosphorous, and hardness removal from reverse osmosis concentrate by microalgae cultivation. WATER RES. 94, 215, 2016.

11. JANCZUKOWICZ W., RODZIEWICZ J., FILIPKOWSKA $\mathrm{U}$. Evaluation of process of biological nitrate and phosphate removal in sbr type reactor with external carbon source. ROCZ OCHR SR. 13, 453, 2011.

12. SONG K.-G., CHO J., CHO K.-W., KIM S.-D., AHN K.-H. Characteristics of simultaneous nitrogen and phosphorus removal in a pilot-scale sequencing anoxic/anaerobic membrane bioreactor at various conditions. Desalination. 250, 801, 2010.

13. BOZORGPOUR F., RAMANDI H.F., JAFARI P., SAMADI S., YAZD S.S., ALIABADI M. Removal of nitrate and phosphate using chitosan $/ \mathrm{Al}_{2} \mathrm{O}_{3} / \mathrm{Fe}_{3} \mathrm{O}_{4}$ composite nanofibrous adsorbent: Comparison with chitosan $/ \mathrm{Al}_{2} \mathrm{O}_{3} / \mathrm{Fe}_{3} \mathrm{O}_{4}$ beads. Int J Biol Macromol. 93, 557, 2016.

14. SAAD R., HAMOUDI S., BELKACEMI K. Adsorption of phosphate and nitrate anions on ammoniumfunctionnalized mesoporous silicas. J POROUS MAT. 15, 3153, 2007.

15. CHENG X., HUANG X., WANG X., SUN D. Influence of calcination on the adsorptive removal of phosphate by $\mathrm{Zn}$ Al layered double hydroxides from excess sludge liquor. J Hazard Mater. 177, 516, 2010.

16. LI K., KUMADA N., YONESAKI Y., TAKEI T., KINOMURA N., WANG H., WANG C. The pH effects on the formation of $\mathrm{Ni} / \mathrm{Al}$ nitrate form layered double hydroxides (LDHs) by chemical precipitation and hydrothermal method. MATER CHEM PHYS. 121, 223, 2010.

17. WANG Y., GAO H. Compositional and structural control on anion sorption capability of layered double hydroxides (LDHs), J Colloid Interface Sci, 301, 19, 2006.

18. HE H., KANG H., MA S., BAI Y., YANG X. High adsorption selectivity of $\mathrm{ZnAl}$ layered double hydroxides and the calcined materials toward phosphate. J Colloid Interface Sci. 343, 225, 2010.

19. OLFS H.W., TORRES-DORANTE L.O., ECKELT R., KOSSLICK H. Comparison of different synthesis routes for Mg-Al layered double hydroxides (LDH): Characterization of the structural phases and anion exchange properties. APPL CLAY SCI. 43, 459, 2009.

20. THEISS F.L., AYOKO G.A., FROST R.L. Removal of iodate $\left(\mathrm{IO}^{3-}\right)$ from aqueous solution using $\mathrm{LDH}$ technology. MATER CHEM PHYS.202, 2017.

21. NOVILLO C., GUAYA D., ALLEN-PERKINS AVENDAÑO A., ARMIJOS C., CORTINA J.L., COTA I. Evaluation of phosphate removal capacity of $\mathrm{Mg} / \mathrm{Al}$ layered double hydroxides from aqueous solutions. Fuel. 138, 72, 2014.

22. SANTOS R.M.M., TRONTO J., BRIOIS V., SANTILLI C.V. Thermal decomposition and recovery properties of $\mathrm{ZnAl}-\mathrm{CO}_{3}$ layered double hydroxide for anionic dye adsorption: insight into the aggregative nucleation and growth mechanism of the LDH memory effect. J. Mater. Chem. A. 5, 9998, 2017. 
23. CAI P., ZHENG H., WANG C., MA, H. HU J., PU Y., LIANG $\mathrm{P}$. Competitive adsorption characteristics of fluoride and phosphate on calcined $\mathrm{Mg}-\mathrm{Al}-\mathrm{CO}_{3}$ layered double hydroxides. J Hazard Mater. 213-214, 100, 2012.

24. CHENG X., HUANG X., WANG X., ZHAO B., CHEN A., SUN D. Phosphate adsorption from sewage sludge filtrate using zinc-aluminum layered double hydroxides. J Hazard Mater. 169, 958, 2009.

25. WU X., WANG Y., XU L., LV L. Removal of perchlorate contaminants by calcined $\mathrm{Zn} / \mathrm{Al}$ layered double hydroxides: Equilibrium, kinetics, and column studies. Desalination. 256,136, 2010.

26. YAO W., YU S., WANG J., ZOU Y., LU S., AI Y., ALHARBI N.S., ALSAEDI A., HAYAT T., WANG $X$. Enhanced removal of methyl orange on calcined glycerol-modified nanocrystallined $\mathrm{Mg} / \mathrm{Al}$ layered double hydroxides. CHEM ENG J. 307, 476, 2017.

27. HALAJNIA A., OUSTAN S., NAJAFI N., KHATAEE A.R., LAKZIAN A. Adsorption-desorption characteristics of nitrate, phosphate and sulfate on $\mathrm{Mg}$-Al layered double hydroxide. APPL CLAY SCI. s 80-81, 305, 2013.

28. YANG K., YAN L.-G., YANG Y.-M., YU S.-J., SHAN R.R., YU H.-Q., ZHU B.-C., DU B. Adsorptive removal of phosphate by $\mathrm{Mg}-\mathrm{Al}$ and $\mathrm{Zn}-\mathrm{Al}$ layered double hydroxides: Kinetics, isotherms and mechanisms. SEP PURIF TECHNOL. 124, 36, 2014.

29. ZHANG M., GAO B., YAO Y., INYANG M. Phosphate removal ability of biochar/MgAl-LDH ultra-fine composites prepared by liquid-phase deposition. Chemosphere. 92, 1042, 2013.

30. ISLAM M., PATEL R. Synthesis and physicochemical characterization of $\mathrm{Zn} / \mathrm{Al}$ chloride layered double hydroxide and evaluation of its nitrate removal efficiency. Desalination. 256, 120, 2015.

31. HIBINO T. Decarbonation Behavior of $\mathrm{Mg}-\mathrm{Al}-\mathrm{CO}_{3}$ Hydrotalcite-like Compounds during Heat Treatment. CLAY CLAY MINER. 43, 427, 1995.
32. ISLAM M., PATEL R. Nitrate sorption by thermally activated $\mathrm{Mg} / \mathrm{Al}$ chloride hydrotalcite-like compound. J Hazard Mater. 169, 524, 2009.

33. CHITRAKAR R., TEZUKA S., HOSOKAWA J., MAKITA Y., SONODA A., OOI K., HIROTSU T. Uptake properties of phosphate on a novel $\mathrm{Zr}$-modified $\mathrm{MgFe}$ LDH(CO $\mathrm{CO}_{3}$. J COLLOID INTERF SCI. 349, 314, 2010.

34. ZHOU J., XU Z.P., QIAO S., LIU Q., XU Y., QIAN G. Enhanced removal of triphosphate by $\mathrm{MgCaFe}-\mathrm{Cl}-\mathrm{LDH}$ : synergism of precipitation with intercalation and surface uptake. J Hazard Mater. 189, 586, 2011.

35. HALAJNIA A., OUSTAN S., NAJAFI N., KHATAEE A.R., LAKZIAN A. The adsorption characteristics of nitrate on $\mathrm{Mg}-\mathrm{Fe}$ and $\mathrm{Mg}-\mathrm{Al}$ layered double hydroxides in a simulated soil solution. APPL CLAY SCI. 70, 28, 2012.

36. ISLAM M., PATEL R. Physicochemical characterization and adsorption behavior of $\mathrm{Ca} / \mathrm{Al}$ chloride hydrotalcitelike compound towards removal of nitrate. J Hazard Mater. 190, 659, 2011

37. YANG Z., ZHANG L., XU P., ZHANG X., NIU X., ZHOU S. The adsorption of nitrate from aqueous solution onto calcined $\mathrm{Mg} / \mathrm{Fe}$ hydrotalcite. DESALIN WATER TREAT. 54, 3400, 2014.

38. ASHEKUZZAMAN S.M., JIANG J.-Q. Study on the sorption-desorption-regeneration performance of $\mathrm{Ca}-, \mathrm{Mg}$ and $\mathrm{CaMg}$-based layered double hydroxides for removing phosphate from water. CHEM ENG J. 246, 97, 2014.

39. GOH K.H., LIM T.T., DONG Z. Application of layered double hydroxides for removal of oxyanions: a review. Water Res. 42, 1343, 2008.

40. TEZUKA S., CHITRAKAR R., SONODA A., OOI K., TOMIDA T. Studies on Selective Adsorbents for OxoAnions. $\mathrm{NO}_{3}^{-}$Adsorptive Properties of Ni-Fe Layered Double Hydroxide in Seawater. ADSORPTION. 11, 751, 2005. 
